\title{
CMA quits global medical body over plagiarism row
}

Cite as: CMAJ 2018 October 29;190:E1290. doi: 10.1503/cmaj.109-5672

Posted on cmajnews.com on Oct. 9, 2018.

$\mathrm{T}$ he Canadian Medical Association (CMA) resigned from the World Medical Association (WMA) on Oct. 6, after the WMA's new president plagiarized portions of his inaugural address from a speech by former CMA president Dr. Chris Simpson.

"As an organization that holds itself as the arbiter of medical ethics at the global level, the WMA has failed to uphold its own standards," CMA President Dr. Gigi Osler said in a statement. "The CMA cannot, in all good conscience, continue to be a member of such an organization."

The plagiarism was uncovered at the WMA annual general assembly in Reykjavik, Iceland. Dr. Leonid Eidelman, chairman of the Israeli Medical Association, was making his inaugural speech as president of the WMA when Simpson, who was attending the meeting as an observer, "heard his own words being said to him", said Dr. Ali Damji, a member of the board of Resident Doctors of Canada (RDoC), who was also at the meeting.

Eidelman's speech included a passage lifted from Simpson's inaugural address as CMA president in 2014: "Every day, we are given the great privilege of being invited into our patients' lives. We are with patients when they are born and when they die; we provide advice and comfort; we prevent illness and treat and manage disease. Our patients trust us and we have always taken our advocacy role very seriously. It is part of the essence of our professionalism."

After the speech, the CMA delegates went through the text and discovered not only the portion taken from Dr. Simpson, but several other passages copied from

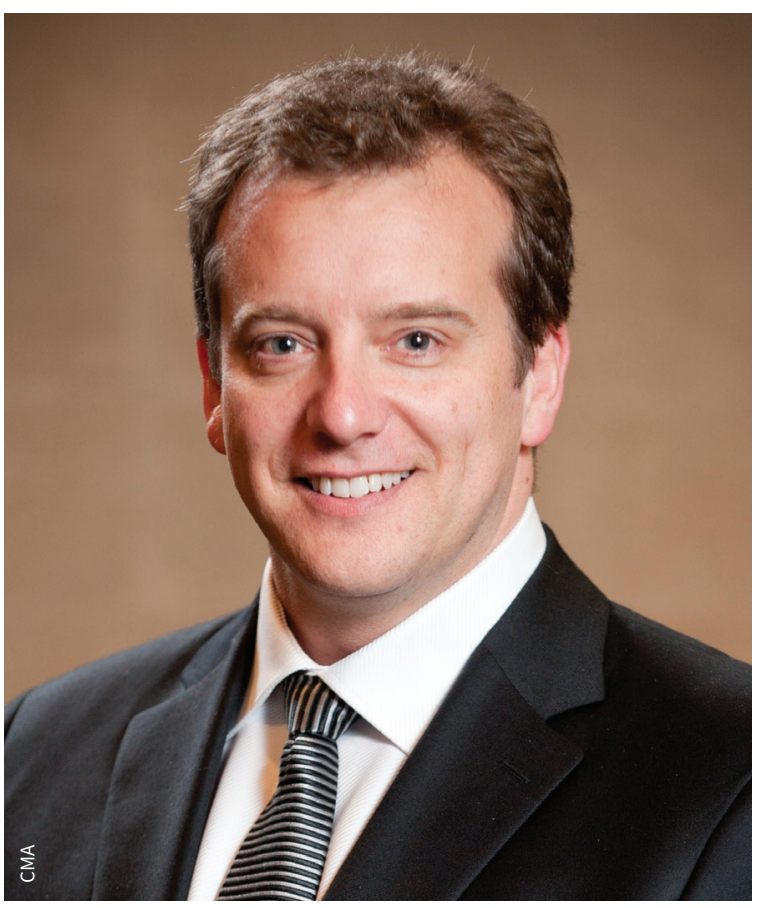

Parts of a speech by former CMA President Dr. Chris Simpson were plagiarized by the new president of the World Medical Association.

websites, blogs and newspaper articles. The text of Eidelman's speech is not currently available on the WMA website.

During the general assembly the next day, Simpson raised the issue. He and Dr. Jeff Blackmer, CMA's vice-president of medical professionalism, read the two speeches simultaneously, driving home the point that it had been plagiarized word for word, said Damji. The CMA delegates said that Eidelman should resign as WMA president, as he had failed to uphold the WMA's own code of ethics. When he refused, the CMA put forward a motion to remove him as president. The WMA council decided not to take up that motion, so the CMA walked out of the organization.

Eidelman apologized to the WMA council and assembly, saying that he had originally written the speech in Hebrew and was unaware of any plagiarism during the translation into English. He subsequently modified the explanation to say the passages came from a speechwriter. But Damji said the explanation was not convincing and did not include an apology to the CMA or Simpson, nor an acknowledgement that as president he is the arbiter of ethics for the WMA. After the apology, Damji also walked out of the meeting on behalf of RDoC in support of CMA. RDoC is also re-evaluating its relationship with WMA.

"The WMA is the global voice of medical ethics and if it cannot hold its highest elected official accountable, how can it aim to deliver on its own purpose of advancing ethics around the world?" said Damji. "Ultimately, what is permitted is condoned, and the message we heard from the WMA is that this type of proven, blatant plagiarism is not something that is taken very seriously."

The WMA issued a statement saying it regretted the resignation of the CMA. "We very much regret Canada's decision. Delegates from the Canadian Medical Association have been valuable participants in WMA affairs for many years. We hope that in time they will return to the association and we will welcome that day," said Dr. Frank Montgomery, vice chairman of the WMA.

The CMA has not said how it will cooperate with other medical associations from around the world in the future. "We will now turn our attention and energy to other ways we can participate in important international initiatives," said Osler.

Brian Owens, St. Stephens, NB 